\title{
STRESS FACTORS AND STRESS MANAGEMENT INTERVENTIONS: THE HEURISTIC OF “BOTTOM UP” AN UPDATE FROM A SYSTEMATIC REVIEW
}

\begin{abstract}
Organizations have increasingly sought to adopt innovative interventions to prevent stressrelated issues. In the field of manufacturing, however, the effectiveness of these interventions remains unclear because a systematic and specific review of existing primary evidence has not been undertaken.

The present systematic literature review sought to address the foregoing limitation in the literature by summarizing the main source of stress and effectiveness of stress management interventions as grounded in the context of manufacturing. Our review was limited to only randomized clinical trials (RCTs) and quasi-experimental studies and concerned employees from the manufacturing sector. Twenty-two studies on primary, secondary and tertiary interventions across four continents (Asia, Europe, USA and South America) were selected and analyzed in terms of stress factors, methodological properties and outcomes. Most of these were RCT studies (68\% Vs $32 \%)$ with a majority of secondary interventions $(\mathrm{N}=11$, $50 \%)$, followed by primary $(\mathrm{N}=5,22 \%)$, tertiary $(\mathrm{N}=3,13 \%)$, and two (9\%) mixed interventions. The main outcomes included an improvement of psychological wellbeing, decreased stress reactivity and an increment of general health. There was a predominance of interventions utilizing skills programs and/or cognitive-behavioral techniques. The main source of stress reported related to professional identity, organizational deficiencies, interpersonal conflicts, physical complaints and poor work environment.

Taken together, the findings provide important theoretical and practical implications for advancing the study of stress factors and the use of stress management interventions in the workplace. The prerequisite for a successful intervention is to address the real problems experienced by professionals and help them to cope with their difficult situations. The strategy of "bottom-up" offers a potential means of enhancing employees' health and wellbeing; however, the most effective means of implementing these interventions needs to be understood better.
\end{abstract}

Keyword: stress, stress management, manufacturing, stress factors, stress consequences 


\section{INTRODUCTION}

Most industrialized countries have experienced crucial job transformations that have been largely determined by important financial, governmental, technological, and social issues (e.g., economic crisis, ageing population). These transformations and the liberalization of trade laws have induced organizations to work competitively, generating high standards of job performance and aggressive rules to compete in a global market (Tate et al., 2014). To succeed in this new global market, "organizations have often reinvented themselves by using management practices such as downsizing or merging with other organizations" (Corbière et al., 2009). This is particularly evident in the manufacturing industry. Indeed, the manufacturing industry is particularly exposed to stress due to contemporary global economic change and a substantial impact has been observed on the health and quality of life of workers as a consequence of global transformations ( $\mathrm{Lu}$ et al., 2017). In the manufacturing industry, a recent analysis conducted by Lu et al. (2017) highlights how the transition to advanced, more technological and competitive environments has resulted in increased workloads and job responsibilities for workers who are now required to perform many tasks and roles much more than workers in other sectors and within time spans that have remained the same. Apart from their specific job roles, workload, lack of sleep, overtime, and shift schedules have been identified as the top main root causes of stress in manufacturing (Mittal et al., 2017).

\section{Stress in organisations}

Stress refers to the physiological and psychological arousal that follows when a person identifies a menace to something of value to him/her and that menace consumes the resources he/she has available to cope with it (Hobfoll, 1989; Lazarus and Folkman, 1984; LePine, LepPine \& Jackson, 2004). Within organisations, stress typically takes two forms (Cohen, 1980; Fiedler, 1992): 1) stress associated with the nature of the task itself (e.g. complexity) or with the conditions of the task (e.g. limited time, poor working conditions) and 2) stress associated with interpersonal relationships of the organisations (e.g. conflict, incomprehension).

Stress problems account for most of the common psycho-emotional disorders causing job absences and inability to work (Tetrick \& Winslow, 2015). Traditionally, stress has been more commonly evaluated in health professions compared to other occupations. However, work-related stress represents a crucial issue for many organisations (e.g., Cartwright \& Cooper, 1997; Cooper \& Marshall, 2013; Karasek \& Theorell, 1992). The prevalence of stress in the work environment is generally reported to be very high: in U.S the percentage is nearly 65\% (http://www.apa.org/helpcenter/work-stress.aspx) while in UK is about $40 \%$ (http://www.hse.gov.uk/statistics/causdis/stress/stress.pdf). There is a growing amount of evidence that stress is not only a particular predisposition to a particular event or situation, but that it is actually important in the aetiology and prognosis of a number of diseases, including death (Cooper \& Marshall, 2013). Stress has been found to be a strong predictor of the development of some diseases such as heart and blood diseases (e.g., Cooper \& Marshall, 2013; Tomei et al., 2000), psychiatric disorders (Leach, Poyser, \& Butterworth, 2016) and their subsequent prognosis in employees. Several reviews and meta-analyses have concluded that stress not only predicts the development of physical and mental ailments in initially 
healthy persons but also in those with established conditions; stress is associated with a relative high risk of recurrent fatal or non-fatal events when the people affected are employed full time (Leach et al., 2016; Milner et al., 2015).

Internationally, many countries have tried to evaluate the negative impact of disorders related to job stress on organisations. The interest in stress management interventions has grown massively. These interventions are designed to improve personal wellbeing and general wellness at the workplace over important aspects of the work environment (at individual, organisational or environmental level) in order to reduce physical or mental strain due to work-related stressors (Murphy \& Hurrell, 1987; Cooper et al., 2001). As a consequence, job stress has represented a central construct in a number of interventions and studies in psychological, occupational and social research. In their review of stress management interventions, LaMontaigne et al. (2007) organized these interventions into three categories by both type (i.e., primary, secondary or tertiary) and level of application (i.e., individual, environment or organization). This review was a first important attempt to evaluate stress management interventions at the general level, in different organisations. Since that review, there has been a growing interest in the research community in developing measurable interventions within organisations. At the same time, there has been an increasing recognition of the complexity of developing workplace interventions (Vanhove et al., 2016).

Based on these considerations, the purpose of the current revision was to assess the literature using LaMontaigne's (2007) conceptualization; to: 1) conduct a systematic review of the most recent literature focused on the manufacturing industry in order to update research in stress management interventions, 2) describe the main stress factors for workers involved in the manufacturing industry, and 3) summarize the significant interventions for stress management in the manufacturing industry.

\section{The theoretical framework}

Two elements are examined here: a) source of stress and b) stress management interventions.

\section{a) Stress Factors}

The review of literature presented in this paper about stress management interventions in industry was not specifically grounded in a precise theoretical framework for defining sources of stress. However, it used the theory of stress by Carson and Kuipers (1998) as a general guide to describe the results. Carson \& Kuipers' model (1998) classified sources of stress into three categories:

1. Specific stressors at the workplace which vary according to the unique problems or strains that each professional group faces (e.g. dealing with strict deadlines by managers or professionals)

2. Stressors that result from major life events (e.g. low social support lack of networks and family relationships).

3. Other stressors that can affect individuals - positively or negatively- the as their power status increases (e.g. some of this stressors, such as high responsibilities, may positively impact psychological and physical wellbeing).

Following this theoretical nomenclature, our current work tried to reframe all the sources of stress included in our reviewed studies into one or more of these categories. 


\section{b) Stress Management Interventions}

A stress management intervention at work is any action or program promoted by an organization that focuses on decreasing the incidence of work-related stressors or on supporting workers to minimalize the negative outcomes of exposure to these stressors (Ivancevich, Matteson, Freedman, \& Phillips, 1990). Although the treatment of stress has reduced the prevalence of detected stress among different worker populations, it has not demonstrated a reduction in subsequent morbidity or mortality. Moreover, it has not demonstrated which interventions are more effective for stress management, especially in manufacturing settings (Egan et al., 2007). Another critical point concerns the theoretical background of the interventions in stress management. The review of literature about stress management interventions is not framed in any particular conceptual model, as literature in this field is very broad and not always defined within a precise theory (Cox, Griffiths, 2010). In view of the type and level of interventions, LaMontaigne et al. (2007) used a matrix of stress management interventions that could be applied in organising results and defining the main outcomes of different studies. The first dimension of their matrix identified the types of intervention as primary, secondary, or tertiary. Primary interventions are "strictly preventive" and try to prevent harm before it occurs and they try to modify organizational settings to enhance workers' wellness. Examples of primary interventions include job reorganization (such as job rotation or job reallocation), changes in the work environment (e.g., providing more comfortable settings), enhancement of social support and the formation of teamwork or the support of health and safety committees. Primary interventions are also commonly referred to as stress prevention programs. Generally, primary interventions are focused on changing aspects of the work environment, but may also focus on characteristics and behaviours of workers thought to be generally important in stress prevention.

Secondary interventions try to empower people to use their abilities to cope with possibly detrimental working situations or to limit the progress of these situations by reinforcing human skills and individual abilities to manage difficulties. This type of intervention focuses on enhancing self-efficacy by offering workers skills to facilitate their adaptation to work environments. Examples of secondary interventions include individual skills training, educational programs and coaching exercises.

Finally, tertiary interventions are targeted at workers who have been harmed in some way by job-related stress. They try to reduce the impact of stress, but the measures are not "preventive". Examples of these interventions include 'return to work programs' or occupational interventions to ameliorate physical complications due to work conditions (e.g., back pain).

The second dimension of LaMontaigne et al.'s (2007) matrix categorises the targets of interventions as: individual, organisational or environmental. Interventions may be directed towards the single worker (employee's skills), or to the formal organisation (e.g., industry's rules and procedures) or the environment (e.g., employee's co-workers, family).

Against the foregoing context, the present paper provides a brief outline of the following research questions:

a) Which are the main source of stress experienced by employees in manufacturing settings?; 
b) Which are the primary, secondary and tertiary interventions for stress management in the workplace with a focus on manufacturing settings?;

c) Which are the individual, organisational and environmental interventions for stress management at the workplace within the manufacturing setting?.

\section{METHOD}

A systematic review was conducted between January and September 2017. The studies considered were research articles dating from 2006 to 2017 . To identify the relevant review literature, we chose a period spanning 11-years: January 2006 - September 2017, as one of the most frequently cited review papers on stress interventions in the organizational setting is LaMontagne et al. (2007), which provides a comprehensive systematic review covering the period of 1990 to 2005. Most of the interventional studies on the subject matter prior to 2006 were captured by LaMontagne et al. (2007). Hence a post-Lamontagne et al. (2007) time period was adopted in our systematic review. An upfront decision was made to search only studies published in English and peer-reviewed journals.

The reviewed studies were identified in 2017 from the following databases: Cochrane Database of Systematic Reviews (CDSR), Ovid MEDLINE(R), EMBASE, ABI/INFORM Global, Business Source Complete, and PsycInfo. To increase the search efficiency, two other databases were searched separately with the aim of identifying the most cited and representative studies about stress-management interventions, and these were: 1) Scopus, and 2) ISI Web of Knowledge.

A comprehensive list of search terms (copy available from authors) was used for common approaches including classifying keywords from the most important published articles, matching keywords in various databases, and consulting with librarians for expert advice on which synonyms and/or relevant phrases to include.

In the first phase, we entered the following search terms on three lines: "stress management," or "stress intervention," or "stress" (TI TITLE) AND Industry* or Manufact* or Entrerprise or Commerc* (ANYWHERE) AND employee or worker (ANYWHERE). In the second phase, we changed the search criteria to two lines: worksite and management, AND stress program or stress intervention (Fig.1). The search returned a total of 409 studies.

The electronic searches were complemented by scanning the reference lists from retrieved articles to identify further articles that may have been missed during the initial search. We also contacted some primary authors for additional data and/or clarification of data, when necessary, to ensure that all relevant articles were represented in the systematic review. Then, we performed a network search and contacted research colleagues knowledgeable in the sector to ask if they could suggest any studies for our consideration. Subsequently, we reviewed all of the studies and chose to include only randomized clinical studies (RCT) or quasi-experimental design studies (i.e. without random assignment) published in English and peer-reviewed journals. These had to include the management of stress as one of their main outcomes (primary or secondary outcomes). The primary outcome represents the greatest benefit of an intervention while a secondary outcome is an additional result monitored to help interpret the results of the primary outcome. 
Finally, we employed a snowball search and reviewed the reference list of each article included to identify additional citations beyond the electronic search. From the initial list of 409 studies, we identified 37 potentially useful articles. However, one of these (Kim et al., 2014) was lacking in regard to study design; another one (Blonk et al., 2006) had insufficient details of the characteristics of the research participants such as whether they were selfemployed; five studies (Cologiuri et al., 2016; Flaxman \& Bond, 2010; Granath et al., 2006; Willert, Thulstrup \& Bonde, 2011; Wolever et al., 2012) were not specifically set in manufacturing contexts; and three reports (Jonas, Leuschner \& Tossmann, 2017; Sjögren et al., 2006; Wang et al., 2007) had non-congruent study outcomes (i.e. burnout, depression), three were not interventions but observational studies (Basnet et al., 2010; Chan et al., 2016; Norder et al., 2014), and two were not randomised properly including poor allocation concealment and selection bias (Tvedt et al., 2009; van Oostrom et al., 2007). Thus, these 15 studies were excluded from our considerations, leaving a net number of 22 studies to be reviewed. Figure 2 shows the flowchart of the delineation of the number of studies that were reviewed.

Within the 22 studies included, we conducted a content analysis of the articles and that was divided into two parts. The first part was aimed at identifying the main stress factors amongst employees while the second evaluated stress management interventions in the frame of the manufacturing industry.

\section{Figure 1. Search strategy}

[Please insert]

\section{Figure 2. Flowchart of the literature search}

[Please insert]

The 22 studies considered were carried out in Asia (nine in Japan, and one each in Iran, India and Thailand), in Europe (four in Sweden, and one each in Denmark, Germany, The Netherlands and Finland), in USA (one study) and in South America (one study in Brazil). In total, we found fifteen (68\%) RCT studies and seven quasi-experimental studies (32\%) (see Table 1).

The sociodemographic information of the participants was not always included. Most of the studies had an imbalance in gender distribution as the great majority of participants were male ( $82 \%$ vs $18 \%$ ). This result was expected and it was related to the fact the most of the industries involved in our revision were typically represented by male employees.

Moreover, the job categories of the employees were not always specified, and office workers out numbered manual workers. Similarly, the two variables of age and work experience were scarcely described, with the exception of the study conducted by Nishiuchi et al. (2007) which explored the relationship between experienced workers (supervisors) and manual workers (forepersons) and the study by Vuori et al. (2011), who addressed stress in relation to immediate career management preparedness and later mental health and intentions to retire early. 
Stress was generally measured using standardized and widely accepted measures such as the Perceived Stress Scale (Cohen et al., 1983); the Brief Job Stress Questionnaire (Shimomitsu et al., 2000) that was mainly used in Japanese studies; and the General Health Questionnaire of the World Organisation of Health (WHO; Ormel et al., 1994). However, on more than one occasion, the authors chose to employ ad hoc interviews to specifically measure stress reduction and stress management.

\section{RESULTS}

\section{Stress Factors}

Embracing the model proposed by Carson and Kuipers (1998), the studies reviewed mainly described source of stress according to the "first category" of analysis identifying the main specific occupational stressors, everyday problems and difficulties. Sources of stress were perceived in different ways by authors, and these differed among managers, office workers and manual workers.

Managers in manufacturing jobs had to deal more frequently with time pressure and job demands (e.g., Eisen Pollak et al., 2008). Work overload was also cited as the reason for negative outcomes in terms of social conflicts (e.g., Sakuraya et al., 2016), problems with evaluations (e.g., Limm et al., 2010) such as loss of opportunity for career development (Sakuraya et al., 2016), and failure at work (e.g., Limm et al., 2010; Rasmussen et al., 2006).

However, some authors described the levels of stress found among manager professionals as moderate or normal for a busy professional (e.g., Nishiuchi et al., 2010). Also, dealing with subordinates was not generally a source of stress. A similar finding was established by Hoa Ly et al. (2014), where leadership skills were not affected by stress.

For office workers, the most relevant job stressors were physical conditions such as working postures (e.g., Eklof \& Hagberg 2006; Jay et al., 2016) or pain (Santos et al., 2010), time constraints (Kojima et al., 2010), job demands (e.g., Bhat et al., 2012; Eklof \& Hagberg, 2006), competition and interpersonal conflicts (e.g., Mino et al., 2006; Umanodan et al., 2014).

Finally, manual workers were exposed to stress factors similar to those of office workers, and they experienced physical complaints with high intensity: the negative characteristics of the job environment had a detrimental consequence on physical (e.g., cardiovascular problems or high blood pressure) and mental health of manual workers (Umanodan, 2009). The stressful characteristics of the environment included the noise level (Eklof \& Hafberg, 2006), indoor climate (Eklof \& Hafberg, 2006), outdoor spaces (Chroobineeh et al., 2011), and poor working stations (Kobayashi et al., 2008). Relationships could also cause much stress for manual workers. Particularly, conflict with colleagues (Tsutsumi et al., 2009), family problems due to being away from home for long periods (Bhat et al., 2012), and other personrelated stress factors such as perfectionism or a high sense of responsibility (van Oostrom et al., 2009) were mentioned most frequently. Organisational settings could also determine stress, and this was related to poor shift work conditions (Solenhill et al., 2016), excessive job demands (Tsutsumi et al., 2009), or static job design (van Oostrom et al., 2009). 
In relation to the other categories, we only found information about the third category; studies mainly evaluated the negative instead of the positive outcomes of stress considering the adverse consequences on physical and emotional wellbeing of the individual within the group-work or organizations. There were only two cases (Nisiuchi et al., 2007; Ly et al., 2014) where stress was conceptualised as normal for managerial professionals.

\section{Table 1. Summary of interventions to increase stress management}

[Please insert Table 1 here]

\section{Stress Management Interventions}

A common understanding deriving from the review of all these interventions is that workrelated stress has become a major occupational risk factor across all manufacturing activities with important consequences at the economic, financial, and social level. An overall and general aim across all the interventions described was to find an innovative way to cope with the economic and social burden of this occupational phenomenon. As Eisen et al. (2008, p. 487) remarked, "stress in the workplace is ubiquitous and increasingly costly [...] Job stress caused health problems that led to decreased productivity [...] and wellness of workers."

With respect to the types of intervention, five studies were primary, twelve were secondary, three were tertiary and two were mixed.

Within the studies reviewed, fourteen of these had stress management as a primary outcome, while eight had stress as a secondary outcome. However, in these latter 8 cases, the study objectives were always aimed at evaluating and improving health in workers with a focus on mental health (Eklof \& Hagberg, 2006; Kojima et al., 2010; Sakuraya et al., 2016), physical health (Choobineh et al., 2011; Jay et al., 2015; Rasmussen et al., 2006; Santos et al., 2010) or lifestyle (Solenhill et al., 2016). Following the previous published review of LaMontaigne et al (2007), we similarly included all types of stress management interventions (using a broad spectrum perspective) comprising but not limited to those focused on physical demands, mental efforts or social requirements, etc.

Regarding the magnitude of the interventions reported, very few studies (Limm et al., 2010; Sakuraya et al., 2016; Shimazu et al., 2006; Umanodam et al., 2009: Vuori et al., 2011) had included a precise calculation of the effect of size (i.e. Cohen's coefficient). However, the strength of an intervention is possible to establish by calculating the mean difference between pre and post intervention.

From the results reported, we identified a significant medium effect ( size $d= \pm 0.25-0.50$ ) with the exception of an intervention that reported a large effect $(\mathrm{d}=0.80)$ on stress management knowledge (Umandodoam et al., 2009). The between and within analyses suggested significant differences in stress across all types of interventions. However, more consistent results could be detected in the primary and secondary interventions while the analyses of the tertiary interventions were less clear and less measureable quantitatively.

\section{The first dimension of the stress management's matrix}




\section{Primary interventions}

A stressful working environment has been recognised as a growing critical issue. Increasing stress management abilities at the organizational level represents an improvement from individual interventions to an active process of organizational modification that allows employees to cope with everyday stress events. We found five studies in this category.

Time organisation plans and goal-setting programs were used to support employees to organise their time in a more profitable way, both on and off the job. Some people often worked under time constraints and were obliged to work on multiple activities at the same time e.g., planning their work schedules effectively and working on concomitant tasks. Using time in that way was clearly demanding and challenging. Umanodam et al. (2009) showed how a time organisation program offered skills for goal definition, programing and selecting tasks; resulting in successfully improving self-efficacy and decreasing stress.

Another useful way to cope with stress at the organizational level is based on teamwork resources. In a Japanese study, a special health occupational board promoted a successful program to reduce worksite stress by improving teamwork and sharing of work activities (Tsutsumi et al., 2009). This organizational change led to a reduction of mental health problems and an improvement of general job performance. Teamwork resources were also used positively by Eklof and Hagberg (2006) in planning an intervention based on the use of "feedback" (reciprocal evaluation) as a general strategy to improve discussions and solutions around emotional stress (e.g., anxiety, scarce social support) and physical stress (e.g., noise level, visual conditions).

Interestingly, increasing creativity was also described as a successful strategy to contain stress, whether demands were consecutive or concurrent. A randomized controlled study showed improvements in work engagement and decrease in stress when using the 'job crafting' technique that permitted workers to re-organise how they conducted their usual tasks (Sakuraya et al., 2016).

We also found some other procedures and strategies which have been implemented successfully for stress management; for example, the study by Kobayashi et al. (2008) showed how the use of practical checklists improves stress management in the work environment. These checklists are a guide for improving work environments and are composed of a number of "good practices" obtained from successful case studies among workplaces for better stress management. They are grouped into several aspects of management like "Participation in work planning", "Ergonomic work methods", "working times arrangements", etc. Examples of good practices are: "Re-arrange the allocation of tasks so as to avoid excessive workload of particular workers", or "Use a notice board to be used by each team for informing all workers of the team correctly", or "Set target hours of and introduce measures to reduce overtime work, e.g. by "non-overtime days" (Kobayashi et al., 2008, p. 469-470). This approach represented a versatile tool particularly for women because it supported a better relationship with supervisors and co-workers and a better communication mechanism for the timely performance of tasks.

\section{Secondary interventions}

We found twelve studies that evaluated secondary interventions: six of these were conducted using a cognitive-behavioural approach (see Table 1). The main stress factors considered in 
these interventions were work overload (e.g., Mino et al., 2006), time constraints (e.g., Kojima et al., 2010) and lack of social support (e.g., Umanodan et al., 2014).

Examples of cognitive-behavioural programs used for intervention were cognitivebehavioural skills exercises, relaxation or meditation programs or deep breathing sessions (Santos et al., 2010; Shimazu et al., 2006). These were often aimed at developing a sense of responsiveness against negative beliefs or irrational views (Limm et al., 2010). These programs are intended to modify people's evaluation of stressful events and their reactions to them (Ly et al., 2014). These cognitive-behavioural programs also teach workers delegation skills and different communication techniques such as assertiveness (Umanodan et al., 2014) which is the individual trait of being self-assured and confident without being aggressive. In some cases, these programs were delivered via the web or computer (Koima et al., 2010; Umanodan et al., 2014).

One of the most recent and common meditation interventions was based on Mindfulness (Ly et al., 2014), which is a particular psychological technique in which people learn to bring their own attention to their internal emotions (i.e., anxiety, terror, angry) and feelings that are arising at the present moment. Mindfulness may be achieved through meditation or other relaxation training sessions that are typical of Buddhist traditions (Kabat-Zinn, 2003).

Although a number of population-based research studies have pointed out that the use of cognitive-behavioural approaches is significantly associated with an increase in health-related Quality of Life (HRQL) and perceived well-being, our review showed that, this approach did not always result in managing stress successfully. While Kojima et al. (2010) and Shimazu et al. (2006) found this approach to be positively associated with a rise in stress knowledge and stress management techniques, other studies produced different results. For instance, the study by Ly et al. (2014), found that mindfulness and, in general, the cognitive-behavioural architecture proposed (Acceptance and Commitment Therapy) were useful in promoting general health, but the intervention was moderately successful in terms of acquiring stress management skills. Eisen et al. (2008) showed that this approach supported the ability to cope with stress in the short term but results were not significant over long periods, especially after one year. Another contrasting result was also reported by Umanodan et al. (2014), where this approach was found to be more useful in improving knowledge about stress rather than supporting the improvement of stress management techniques.

Asian cultural influences were also apparent for other secondary interventions that were not framed in a cognitive-behavioural approach. This is the case of the study conducted by Bhat et al. (2012), who used yoga sessions which were organised to improve workers' ability to cope with stressful situations. This technique has shown positive results in term of stress management and general wellbeing.

Finally, other secondary interventions concerned participatory activities such as involvement in seminars, workshops or role-playing activities. The act of role-playing represents a successful way to gradually learn how to express one's emotions related to a stressful situation (Nishiuchi et al., 2007). Role-playing has been conducted in sessions involving both individuals (Limm et al., 2010) and groups (Nishiuchi et al., 2007), with positive results measurable at the physical level (e.g., cortisol and salivary $\alpha$-amylase) and at the emotional level (mood). Role-playing has also been positively associated with assertiveness at work (Vuori et al., 2011). In the study by Vuori et al., (2011), role-playing was used to successfully 
orient career management preparedness, improve employees' ability to deal with stress and increase general emotional wellbeing.

\section{Tertiary interventions}

Tertiary interventions were aimed at minimising the effects of stress-related problems once they were developed, through management or treatment of symptoms or disease. In total we found five studies (see Table 1.); two of these were mixed as primary/tertiary as they were targeted at both healthy and non-healthy (sick or injured) workers (Choobineh et al., 2009; Rasmussesn et al., 2006). Three studies were conducted in Europe (Denmark, Sweden and the Netherlands) and two in Asia (Iran and Thailand).

Apart from the study of Jay et al. (2015), all of the other studies employed the use of multiple benefit factors in promoting individual wellbeing in the workplace, restoring physical health status, and protecting the health of employees. These interventions showed positive effects on stress management (Choobineeh et al., 2011; van Oostrom et al., 2009).

Interestingly, Choobineeh et al., (2011) found an improvement of stress management skills as a result of improved workers' awareness of physical risk factors, and also as a result of a better communication among colleagues.

Most of the interventions (three out of five) were framed in an ergonomic approach, and consisted of tailored physical exercises and a variety of rehabilitation training activities ranging from motor control movements to yoga sessions. Jay et al. (2015) combined ergonomic training with individual activities to equip workers affected by chronic musculoskeletal pain with knowledge, skills and resources (typical of secondary interventions). The studies by Rasmussen et al. (2006) and Von Oostrom et al. (2009) differed from the others since they were primarily focused on group discussions and brainstorming sessions with injured workers and staff members. The dialog and reflection activities used in both studies were positively correlated with the improvement of stress management skills. Moreover, the methodology proposed by Von Oostrom et al. (2009), that is, intervention mapping based on progressive steps and gradual implementation, resulted in a successful example of measurable and evidence-based intervention.

\section{The second dimension of the stress management's matrix}

A vast majority of the interventions were categorised as individual (16 out of 22, 73\%) as they were targeted at the single worker. These worksite interventions were often directed towards the individuals (and not towards the organisation or the environment) through the utilisation of specific and tailored techniques e.g., relaxation, meditation, etc. Focusing on the individual, these interventions had a positive impact on worker wellness as they reduced feelings of stress among workers; furthered their knowledge of stress factors; and raised their level of motivation and satisfaction.

We found two interventions targeted at the work environment. The first of these by Eklof and Hagberg (2006) analyzed relationships between office workers and supervisors using structured working groups and based on the 'feedback technique'; while the study by van Oostrom et al. (2009) was based on planned meetings and task analysis with different members of staff (i.e., supervisor, HR) and workers. Both approaches produced successful results in terms of stress management and satisfaction. 
Finally, we found only one intervention that targeted the organization. Here, new procedures and rules and job designation were structured to favour better distress management and an improvement of workers' mental health (Tsutumi et al., 2009). This intervention was positively associated with better stress management and the general health of workers.

\section{DISCUSSION}

As argued by Cox and Griffiths (2010), the evaluation of work stress interventions is challenging; there is still an open debate about how to frame and conceptualise interventions and the methodology that supports them. "The decision about which type of intervention to use should be based on a thorough assessment of the specific situation rather some general principles" (Briner \& Reynolds, 1999, p. 658). Interventions have to be designed to fit the specific organizational context in which they are implemented, and cannot be conducted using general theoretical principles solely. Interventions have to be ecologically valid and measurable. Embracing this perspective, this current work has tried to evaluate recent literature about stress management interventions within the frame of the manufacturing industry, and paid attention to both the heterogeneity of settings and measurability of stress outcomes.

In total, twenty-two interventions from 2006 to 2017 were selected. It is important to highlight that we found a balanced number of interventions published each year (except for 2007), suggesting a continuous interest in organisation and occupational research on stress management interventions. The interest in stress management in the manufacturing industry is also cross-continental. We found interventions in four continents (Europe, Asia, USA and South America), with a prevalence of studies in Southeast Asia (particularly in Japan). This datum is interesting and innovative; while many interventions are generally conducted in Europe (LaMontaigne et al., 2007) the controlled interventions focused on the manufacturing industry are more frequent in Asia.

It could be argued that the number of interventions selected was quite restricted considering the interest in stress management in the last two decades. Our selection was primarily guided by the use of a reasonable rigorous methodology to evaluate the interventions, and on that basis we selected only RCT or quasi-experimental evaluation design as the inclusion criteria of our review. We had to exclude a number of studies mainly because they: did not concern the manufacturing sector, had a non-controlled design or poor randomisation properties applied.

Even though the main focus of the studies selected was stress management, the types and levels of the interventions differed considerably. Half of the studies reviewed were secondary, and the presence of primary and tertiary interventions was modest. Interestingly, two studies were mixed; one focused on primary and secondary interventions, and one focused on secondary and tertiary interventions simultaneously. This result is in line with previous publications (e.g., Corbière et al., 2009; LaMontaigne et al., 2007), confirming the tendency to apply secondary interventions in organisational settings, which are probably less arduous to plan and less expensive than primary or tertiary interventions (Corbière et al., 2009). 
In terms of the types of target, most of the interventions took place at the individual level. As Corbière et al. suggested "most organisations have a tendency to favour stress management programs at an individual level because of the reduced risk associated with their implementation" (2009, p. 82). Indeed, individual interventions are generally less expensive and do not portend substantial changes inside the organisations in terms of rules and procedures. However, LaMontaigne et al. (2007) commented in their review that, it was important to intervene across the dimensions (individual and organisational; or individual and environmental) in order to connect the development of individual skills with the resources promoted by the organisation.

Regarding the sources of stress, we were able to identify the first category of stressors (Carson and Kuipers, 1998). The occupational stressors showed a wide heterogeneity across the studies. The most important sources of stress in manufacturing included: a) professional identity such as no opportunity for career development or lack of evaluations, b) organizational deficiencies such as work overload and job demands, c) interpersonal conflicts such as scarce social support or absence of workplace, d) physical complaints such as physical discomfort, muscular contractions or concentration, and e) the work environment such as indoor /outdoor spaces and activities. However, our review was not able to determine the effect of socio-demographic factors on these stressors. The significant factors leading to employees becoming prone to stress were not separated by gender, age or level of education; most of the studies included in the review were done with males, while others did not differentiate either the level of career of the different employees or their level of experience.

Other sources of stress (the third category of stressors included in the model) were also found in our review (Carson \& Kuipers, 1998) and they were largely conceptualised as negative. This means that stress is described as maladaptive for the organisations. In general, these interventions were planned to prevent or cope with the detrimental consequences of stress, such as illness, exhaustion or loss of motivation at work. However, in a few cases, some authors highlighted how stress, even when it is not positive, may be considered adaptive. Particularly in the managerial field, some authors described the levels of stress found among professionals as moderate or tolerable (e.g., Nishiuchi et al., 2007). Also, dealing with subordinates was not generally considered as a stressful factor (e.g., Ly et al., 2014). One reason for this might be that managers choose to work in this area of industry with a prior knowledge of the high demands from their clients (both private and industry) and the nature of services their work entails, which indirectly implies leadership and management ability.

Examining the stress management interventions revealed that the studies included in our review have covered a range of topics. Across all the studies considered, the interventions were generally successful; reporting a significant moderate effect on the mean.

Most of the interventions described were secondary, and most of these were framed in the cognitive-behavioural approach. As Shimazu et al. (2006, p. 61) highlighted in their study, "cognitive-behavioural interventions appear particularly effective in tasks with high job control because high control allows employees to exercise the coping skills they have learnt through an intervention program." More precisely, people's thoughts regulate their feelings and behaviour. In this regard, the development of effective strategies to manage stress is related to the acquisition of individual skills through meditation and committed actions. 
Mental restructuring actions (Kojima et al., 2010) and communication skills are beneficial for coping with emotional problems such as depression or anxiety (Umanodan et al., 2014). Not all of the behavioural programs were equally successful in stress management. However, the intensity of self-training sessions can produce a difference in the acquisition of coping strategies for handling stressful situations (Kojima et al., 2010; Umanodan et al., 2014). From the results of our literature review, more effective tailored strategies need to be implemented at both the individual and organisational level in order to reduce the impact which the many identified stressors have on employees' work and home lives. The effectiveness of specific stress management techniques needs to be tested empirically in more depth when clinical interventions are applied.

For primary and tertiary interventions, we found that these actions were generally not grounded in a specific theoretical approach and were conducted by a number of professionals from different curricula. However, in term of effectiveness they all resulted in the improvement of stress management skills (despite that the tertiary interventions were sometimes lacking in information that described the magnitude of the effect on the program). More training and education should be given in these programs so that employees may then be able to implement them usefully to enhance their own mental and physical wellbeing in managing stressful situations.

The current review of the literature may raise questions due to the heterogeneity of the study population. We focused on the manufacturing industry that is characterised by different job categories, qualifications and job activities. Our initial intention was to individualise three lines of employees: managers, office workers and manual workers. Although these three categories differ in terms of responsibilities, tasks and roles, we decided to review the current literature without focusing on one specific job category. This was determined in part by the approach used by previous similar literature reviews (e.g. LaMontaigne et al., 2007: Corbière et al., 2009) and, in part, by our analysis, which found that interventions are generally conducted by grouping together different types of workers. Second, we found similar stress factors across job categories. For example, social conflicts (e.g., Sakuraya et al., 2016), problems with evaluations (e.g., Limm et al., 2010) and failure at work (e.g., Limm et al., 2010; Rasmussen et al., 2006) are common stress factors among different types of workers. Physical complaints were also found to be similar in both manual and office workers. Only one study differed; that of Jay et al. (2015), which was focused on laboratory technicians. We decided to retain this study within our analysis because this category of workers did not describe stress very differently from office workers. The activity of laboratory technicians' is characterized by extended periods of time spent in static postures (displaying sustained lowforce muscular contractions as well as repetitive precision movements) requiring high concentration. These positions cause much stress (mental and physical) among workers. However, static postures and repetitive precise movements are also commonly reported by many office workers.

It is important to evaluate our findings in light of the review by LaMontagne et al. (2007), which represents one of the most important frames of reference on the subject matter. Thus, we took LaMontagne's review as a frame of reference and forward-looking point for selecting our review papers and conducting our research. 
The work conducted by LaMontagne et al. (2007) represented an excellent example of literature synthesis among a very huge and wide literature across different disciplines and sectors; their review did a very interesting quantitative (rather than a qualitative) analysis of the number of primary, secondary and tertiary interventions and the level of targeting of these interventions. Their work also gave an interesting picture of the prevalent practice of stress management with workers involved in different sectors. Likewise, we considered the inclusion of a wide perspective of possible interventions not limited to a single or similar approaches to stress management but adopting a wide-ranging perspective of practice from re-organisation of worktime to participation in work activities, taking experiences from Psychology, Ergonomics, Occupational studies, Medicine, Management and Administration research.

As reported by LaMontagne et al. (2007) in their landmark literature review: "There is a growing interest in intervention strategies that integrate occupational health and workplace health promotion" (p. 276) working on different variables related to stress from work reorganisation to physical fitness or health behaviours. While we incorporated most of the criteria and the guidelines of the past review, we also opted to insert new strategies to better compare and measure our studies.

While one of the main strengths of the LaMontaigne et al.'s (2007) review is breadth and heterogeneity, one of the main weaknesses they found was the poor level of comparability and replicability of the studies they considered. Based on that important consideration, we chose to limit our search to controlled studies (quasi-experimental and randomised) and focused on the manufacturing industry.

One main limitation we found in the LaMontaigne et al. (2007) treatise is that their review integrated different types of interventions (from observational case studies to randomised) in different organisational settings, ranging from manufacturing to public administration (e.g., bus drivers) or health (e.g., hospital) that have different characteristics and features than an industrial context. A main difference that characterises the manufacturing sector which we considered is that, manufacturing industries are strongly affected by production and market competitiveness that, in turn, are the basis of different practices, rules and procedures that may cause stress to their employees at different levels.

As the review of John (2006) argued, the context is fundamental for evaluating the implementation and the success of an intervention within a particular organisation. Successful interventions have to be tailored within specific contexts and have to meet the specific needs of their workers. Within the specific context of the manufacturing industry (oriented to markets and profit), an important criterion for the success of stress intervention seems to be the promotion of flexibility; which is transversal to primary, secondary and tertiary intervention and from the individual to environmental level. Flexibility is a "compass" for the implementation of a variety of practices and policies preventing stress from job activity reorganisation, individual empowerment education and environmental measures to protect a balance between work and personal life. Flexibility shapes itself from the characteristics of each environment and it adapts over time. Flexibility draws attention to the "bottom up" perspective. A bottom up perspective originates from the context (people, needs, requirements) -that is the bottom-, considers the final objective, and induces action to 
construct a sequential path organized in successive passages which are not pre-determined but grounded with the context and generally built with intuition (heuristic way).

Some technique such as the use of feedback, practical tools like checklists, individual strategies of relaxation, communication assertiveness, dialog and reflection, rules and job designation are all resources that shape themselves from the bottom, from the needs of people and from the necessities of the organisation; and they follow a strategically (heuristically) successful way to cope with stress.

There are some limitations to the analysis of the studies we reviewed. Firstly, in many of the original papers the reporting of the interventions was generally difficult to measure. There was often a lack of evidence on whether the interventions were realised fully or even partially. Secondly, some of the described instruments used to detect stress were not always compared appropriately. Most instruments were questionnaires (scales or self-reported measures), and the period of follow-up ranged from one week to one year, but in many cases the timescale was not well described. Further, corrections for confounding variables were often scarcely reported or non-existent. Thirdly, six of the interventions were reported as quasi-experimental studies, and this might have interfered with internal validity. The assumptions and methodological aspects argued here should be fully evaluated, both in the interpretation of existing studies and in the design of future stress management interventions. Lastly, we need to highlight that the interventions included in our review covered only some and not all manufacturing sub-sectors.

\section{CONCLUSION}

This systematic review of stress management interventions has identified a number of health benefits occurring when employees become able to control stressful situations. There are different implications resulting from the results of this review. High levels of stress among workers may have a negative impact on their ability to efficiently perform different and especially highly demanding tasks. Education and programs using different approaches are needed to help professionals working in manufacturing jobs to deal with different stressors inherent in their challenging and physically and cognitively demanding work. The prerequisite of a successful intervention is to address the real problems (physical, mental or social) experienced by employees and help them to cope with their difficult situations. If we want stress to be approached as a flexible and preventable state, a bottom-up perspective is required (Demerouti et al., 2017). Not only should the real problems and wishes of workers be listened to, the tools through which stress can be measured should also be designed in relation to each context and used properly including structured follow-up examinations. This bottom-up perspective warrants the involvement of workers and human resources departments of organizations in the identification of needs and interventions (at the individual, organisational and environmental level), and enhancement of useful coping strategies whileaddressing the negative ones.

Stress screening could be implemented by organisations as an internal periodical process, facilitating referral of workers with specific, identified health needs to appropriate care and treatment services; so as to ensure that preventive measures are applied in a timely manner. 
This screening could also inform the formulation of an intervention policy and provide information to organizations on high-risk job-workers. Nevertheless, work to enable a better understanding of the controllability and management of stress and the possibilities of prevention (particularly implementing controlled studies) should be accomplished for such endeavours to be more widely successful.

The evidence from this review recommends a rethink of workplaces by managing their stressful and difficult environments more consciously, making it possible to enhance employees' involvement and control. Stress management interventions offer a potential means of augmenting employees' health and well-being, although more remains to be understood about the most effective means of implementing these interventions.

\section{COMPETING INTERESTS}

The authors declare that they have no competing interests.

\section{ACKNOWLEDGMENT}

The first author is a Marie Sklodowska Curie Fellow and acknowledges support from the EC project H2020-MSCA-IF-2015/H2020-MSCA-IF-2015, Grant Agreement: 703236 'Inhibiting Stress in the Construction Industry' (INSTINCT). This review is part of the ongoing INSTINCT project (www.instinctproject.eu), and the authors are grateful for the Marie Sklodowska Curie Individual Fellowship grant which enabled it.

\section{AUTHORS' CONTRIBUTIONS}

SR carried out the literature review, performed the literature analysis, participated in the design of the study and drafted the manuscript. EC, performed the literature analysis, participated in the design of the study and drafted the manuscript. $\mathrm{PH}$ participated in the design of the study and reviewed the manuscript. All authors read and approved the final manuscript.

\section{REFERENCES}

1. Basnet, P., Gurung, S., Pal, R., Kar, S., \& Bharati, D. R. (2010). Occupational stress among tunnel workers in Sikkim. Industrial psychiatry journal, 19(1), 13-19.

2. Bhat, P. S., Chopra, V., Mehta, S. G., Srivastava, K., Kumar, S. R., \& Prakash, J. (2012). Psychological benefits of yoga in industrial workers. Industrial psychiatry journal, 21(2), 98-103.

3. Blonk, R. W., Brenninkmeijer, V., Lagerveld, S. E., \& Houtman, I. L. (2006). Return to work: A comparison of two cognitive behavioural interventions in cases of workrelated psychological complaints among the self-employed. Work \& Stress, 20(2), 129-144.

4. Briner, R. B., \& Reynolds, S. (1999). The costs, benefits, and limitations of organizational level stress interventions. Journal of Organizational Behavior, 20(5), 647-664. 
5. Calogiuri, G., Evensen, K., Weydahl, A., Andersson, K., Patil, G., Ihlebæk, C., \& Raanaas, R. K. (2016). Green exercise as a workplace intervention to reduce job stress. Results from a pilot study. Work, 53(1), 99-111.

6. Carson, J., \& Kuipers, E. (1998). Stress management interventions. In Hardy, S., Carson, J., Thomas, B. (eds). Occupational stress: Personal and professional approaches, Stanley Thornes Ltd, London, UK, 157-174.

7. Cartwright, S., \& Cooper, C. L. (1997). Managing workplace stress. Thousand Oaks, California: Sage.

8. Chan, I. Y. S., Leung, M. Y., \& Liu, A. M. M. (2016). Occupational health management system: A study of expatriate construction professionals. Accident Analysis \& Prevention, 93(8), 280-290.

9. Choobineh, A., Motamedzade, M., Kazemi, M., Moghimbeigi, A., \& Pahlavian, A. H. (2011). The impact of ergonomics intervention on psychosocial factors and musculoskeletal symptoms among office workers. International Journal of Industry Ergonomics, 41(6), 671-676.

10. Cohen, S. (1980). After effects of stress on human performance and social behavior: A review of research and theory. Psychological Bulletin, 88, 82-108.

11. Corbière, M., Shen, J., Rouleau, M., \& Dewa, C. S. (2009). A systematic review of preventive interventions regarding mental health issues in organizations. Work, 33(1), 81-116.

12. Cohen, S., Kamarck, T., and Mermelstein, R. (1983). A global measure of perceived stress. Journal of Health and Social Behavior, 24(4), 386-396.

13. Cooper, C. L., Dewe, P. J., \& O'Driscoll, M. P. (2001). Organizational stress: A review and critique of theory, research, and applications. Thousand Oaks, California: Sage.

14. Cooper C.L., Marshall J. (2013) Occupational Sources of Stress: A Review of the Literature Relating to Coronary Heart Disease and Mental Ill Health. In: Cooper C.L. (eds) From Stress to Wellbeing Volume 1. Palgrave Macmillan, London, 3-23.

15. Cox, T., \& Griffiths, A. (2010). Work-related stress: A theoretical perspective. In: Leka, S. and Houdmont, J., (Eds.). A textbook of occupational health psychology. Wiley-Blackwell, Oxford, 31-56.

16. Demerouti, E., Van den Heuvel, M., Xanthopoulou, D., Dubbelt, L., \& Gordon, H. J. (2017). Job resources as contributors to wellbeing. In. Cary, Cooper \& Leiter (Eds). The Routledge Companion to Wellbeing at Work, New York, 269-283.

17. Egan, M., Bambra, C., Thomas, S., Petticrew, M., Whitehead, M., \& Thomson, H. (2007). The psychosocial and health effects of workplace reorganisation. 1. A systematic review of organisational-level interventions that aim to increase employee control. Journal of epidemiology and community health, 61(11), 945-954.

18. Eisen, P. K., Allen, G. J., Bollash, M., \& Pescatello, L. S. (2008). Stress management in the workplace: A comparison of a computer-based and an in-person stressmanagement intervention. Computers in Human Behavior, 24(2), 486-496.

19. Eklöf, M., \& Hagberg, M. (2006). Are simple feedback interventions involving workplace data associated with better working environment and health? A cluster randomized controlled study among Swedish VDU workers. Applied Ergonomics, 37(2), 201-210.

20. Fiedler, F. (1992). Time-based measures of leader experience and organizational performance: A review of research and a preliminary model. The Leadership Quarterly, 3, 5-23. 
21. Flaxman, P. E., \& Bond, F. W. (2010). A randomised worksite comparison of acceptance and commitment therapy and stress inoculation training. Behaviour Research and Therapy, 48(8), 816-820.

22. Granath, J., Ingvarsson, S., von Thiele, U., \& Lundberg, U. (2006). Stress management: a randomized study of cognitive behavioural therapy and yoga. Cognitive Behaviour Therapy, 35(1), 3-10.

23. Hobfoll, S. E. (1989). Conservation of resources: A new attempt at conceptualizing stress. American Psychologist, 44, 513-524.

24. Hurrell, J. J., \& Murphy, L. R. (1996). Occupational stress intervention. American Journal of Industrial Medicine, 29(4), 338-341.

25. Ivancevich, J. M., Matteson, M. T., Freedman, S. M., \& Phillips, J. S. (1990). Worksite stress management interventions. American Psychologist, 45, 252-261.

26. Jay, K., Brandt, M., Hansen, K., Sundstrup, E., Jakobsen, M. D., Schraefel, M. C., \& Andersen, L. L. (2015). Effect of individually tailored biopsychosocial workplace interventions on chronic musculoskeletal pain and stress among laboratory technicians: randomized controlled trial. Pain Physician, 18(5), 459-471.

27. Jonas, B., Leuschner, F., \& Tossmann, P. (2017). Efficacy of an internet-based intervention for burnout: a randomized controlled trial in the German working population. Anxiety, Stress, \& Coping, 30(2), 133-144.

28. Kabat-Zinn, J. (2003). Mindfulness-based interventions in context: past, present, and future. Clinical psychology. Science and practice, 10(2), 144-156.

29. Karasek, R., \& Theorell, T. (1992). Healthy work: stress, productivity, and the reconstruction of working life. New York: Basic books.

30. Kobayashi, Y., Kaneyoshi, A., Yokota, A., \& Kawakami, N. (2008). Effects of a worker participatory program for improving work environments on job stressors and mental health among workers: a controlled trial. Journal of Occupational Health, 50(6), 455-470.

31. Kojima, R., Fujisawa, D., Tajima, M., Shibaoka, M., Kakinuma, M., Shima, S., \& Yutaka, O. N. O. (2010). Efficacy of cognitive behavioral therapy training using brief e-mail sessions in the workplace: a controlled clinical trial. Industrial Health, 48(4), 495-502.

32. Lamontagne, A. D., Keegel, T., Louie, A. M., Ostry, A., \& Landsbergis, P. A. (2007). A systematic review of the job-stress intervention evaluation literature, 19902005. International Journal of Occupational and Environmental Health, 13(3), 268280.

33. Lazarus, R. S., \& Folkman, S. (1984). Stress, appraisal, and coping. New York: Springer Publishing Company, Inc.

34. Leach, L. S., Poyser, C., \& Butterworth, P. (2017). Workplace bullying and the association with suicidal ideation/thoughts and behaviour: a systematic review. Occupational \& Environmental Medicine, 74(1),72-79.

35. LePine, J., LepPine, M., \& Jackson, C. (2004). Challenge and hindrance stress: Relationships with exhaustion, motivation to learn, and learning performance. Journal of Applied Psychology, 89, 883-891.

36. Limm, H., Gündel, H., Heinmüller, M., Marten-Mittag, B., Nater, U. M., Siegrist, J., \& Angerer, P. (2010). Stress management interventions in the workplace improve stress reactivity: a randomised controlled trial. Occupational \& Environmental Medicine, 68(2), 126-133.

37. Ly, K. H., Asplund, K., \& Andersson, G. (2014). Stress management for middle managers via an acceptance and commitment-based smartphone application: A randomized controlled trial. Internet Interventions, 1(3), 95-101. 
38. Lu, L., Megahed, F. M., Sesek, R. F., \& Cavuoto, L. A. (2017). A survey of the prevalence of fatigue, its precursors and individual coping mechanisms among US manufacturing workers. Applied Ergonomics, 65(11), 139-151.

39. Milner, A., Page, K., Spencer-Thomas, S., \& Lamotagne, A. D. (2015). Workplace suicide prevention: a systematic review of published and unpublished activities. Health Promotion International, 30(1), 29-37.

40. Mittal, K., Singh, K., \& Sharma, G. (2017). Work-Life Balance and Employee Health: A Cross-Sectional Analysis of Manufacturing and Service Sectors. Prabandhan: Indian Journal of Management, 10(7), 34-49.

41. Mino, Y., Babazono, A., Tsuda, T., \& Yasuda, N. (2006). Can stress management at the workplace prevent depression? A randomized controlled trial. Psychotherapy and Psychosomatics, 75(3), 177-182.

42. Nishiuchi, K., Tsutsumi, A., Takao, S., Mineyama, S., \& Kawakami, N. (2007). Effects of an education program for stress reduction on supervisor knowledge, attitudes, and behavior in the workplace: a randomized controlled trial. Journal of Occupational Health, 49(3), 190-198.

43. Norder, G., Bültmann, U., Hoedeman, R., Bruin, J. D., van der Klink, J. J., \& Roelen, C. A. (2014). Recovery and recurrence of mental sickness absence among production and office workers in the industrial sector. The European Journal of Public Health, 25(3), 419-423.

44. Ormel, J., VonKorff, M., Ustun, T. B., Pini, S., Korten, A., \& Oldehinkel, T. (1994). Common mental disorders and disability across cultures: results from the WHO Collaborative Study on Psychological Problems in General Health Care. Journal of the American Medical Association, 272(22), 1741-1748.

45. Rachiwong, S., Panasiriwong, P., Saosomphop, J., Widjaja, W., \& Ajjimaporn, A. (2015). Effects of modified hatha yoga in industrial rehabilitation on physical fitness and stress of injured workers. Journal of Occupational Rehabilitation, 25(3), 669-674.

46. Rasmussen, K., Glasscock, D. J., Hansen, O. N., Carstensen, O., Jepsen, J. F., \& Nielsen, K. J. (2006). Worker participation in change processes in a Danish Industry setting. American Journal of Industry Medicine, 49(9), 767-779.

47. Sakuraya, A., Shimazu, A., Imamura, K., Namba, K., \& Kawakami, N. (2016). Effects of a job crafting intervention program on work engagement among Japanese employees: a pretest-posttest study. BMC Psychology, 4(1), 49.

48. Santos, A. C., Bredemeier, M., Rosa, K. F., Amantéa, V. A., \& Xavier, R. M. (2011). Impact on the Quality of Life of an Educational Program for the Prevention of WorkRelated Musculoskeletal Disorders: a randomized controlled trial. BMC public health, 11(1), 60, [Online] https://doi.org/10.1186/1471-2458-11-60 (Accesed on November $\left.17^{\text {th }}, 2017\right)$

49. Shimazu, A., Umanodan, R., \& Schaufeli, W. B. (2006). Effects of a brief worksite stress management program on coping skills, psychological distress and physical complaints: a controlled trial. International Archives of Occupational and Environmental Health, 80(1), 60-69.

50. Shimomitsu T, Haratani T, Nakamura K, Kawakami N, Hayashi T, Hiro H, Arai M, Miyazaki S, Furuki K, Ohya Y, Odagiri Y .(2000) Final development of the Brief Job Stress Questionnaire mainly used for assessment of the individuals. In: Kato M (Ed.), The Ministry of Labor sponsored grant for the prevention of work-related illness, FY 1999 report, Tokyo: Tokyo Medical University, pp.126-64.

51. Sjögren, T., Nissinen, K. J., Järvenpää, S. K., Ojanen, M. T., Vanharanta, H., \& Mälkiä, E. A. (2006). Effects of a physical exercise intervention on subjective physical well-being, psychosocial functioning and general well-being among office 
workers: A cluster randomized-controlled cross-over design. Scandinavian journal of medicine \& science in sports, 16(6), 381-390.

52. Solenhill, M., Grotta, A., Pasquali, E., Bakkman, L., Bellocco, R., \& Trolle Lagerros, Y. (2016). The Effect of Tailored Web-Based Feedback and Optional Telephone Coaching on Health Improvements: A Randomized Intervention Among Employees in the Transport Service Industry. Journal of Medical Internet Research, 18(8), e158. [Online] http://doi.org/10.2196/jmir.4005 (Accessed on November 17 ${ }^{\text {th }}, 2017$ ).

53. Tate, W. L., Ellram, L. M., Schoenherr, T., \& Petersen, K. J. (2014). Global competitive conditions driving the manufacturing location decision. Business Horizons, 57(3), 381-390.

54. Tomei, F., Baccolo, T. P., Izzo, A., Papaleo, B., Persechino, B., Tomao, E., \& Rosati, M. V. (2000). Occupational Cardiovascular Risk Factors. In Chang, J.B., Prasad, K., Olsen, E.R., Sumpio, B.E. (Eds.) Textbook of Angiology. New York: Springer, pp. 141-161.

55. Tetrick, L. E., \& Winslow, C. J. (2015). Workplace stress management interventions and health promotion. Annual Review of Organizational Psychology and Organizational Behavior, 2(1), 583-603.

56. Tsutsumi, A., Nagami, M., Yoshikawa, T., Kogi, K., \& Kawakami, N. (2009). Participatory intervention for workplace improvements on mental health and job performance among blue-collar workers: a cluster randomized controlled trial. Journal of Occupational and Environmental Medicine, 51(5), 554-563.

57. Tvedt, S. D., Saksvik, P. Ø., \& Nytr $\oslash$, K. (2009). Does change process healthiness reduce the negative effects of organizational change on the psychosocial work environment? Work \& Stress, 23(1), 80-98.

58. Umanodan, R., Kobayashi, Y., Nakamura, M., Kitaoka-Higashiguchi, K., Kawakami, N., \& Shimazu, A. (2009). Effects of a worksite stress management training program with six short-hour sessions: a controlled trial among Japanese employees. Journal of occupational health, 51(4), 294-302.

59. Umanodan, R., Shimazu, A., Minami, M., \& Kawakami, N. (2014). Effects of Computer-based Stress Management Training on Psychological Well-being and Work Performance in Japanese Employees: A Cluster Randomized Controlled Trial. Industrial health, 52(6), 480-491.

60. Vanhove, A. J., Herian, M. N., Perez, A. L., Harms, P. D., \& Lester, P. B. (2016). Can resilience be developed at work? A meta-analytic review of resilience-building programme effectiveness. Journal of Occupational and Organizational Psychology, 89(2), 278-307.

61. van Oostrom, S. H., Anema, J. R., Terluin, B., Venema, A., de Vet, H. C., \& van Mechelen, W. (2007). Development of a workplace intervention for sick-listed employees with stress-related mental disorders: Intervention Mapping as a useful tool. BMC health services research, 7(1), 127.

62. van Oostrom, S. H., van Mechelen, W., Terluin, B., de Vet, H. C., \& Anema, J. R. (2009). A participatory workplace intervention for employees with distress and lost time: a feasibility evaluation within a randomized controlled trial. Journal of Occupational Rehabilitation, 19(2), 212-222.

63. Vuori, J., Toppinen-Tanner, S., \& Mutanen, P. (2012). Effects of resource-building group intervention on career management and mental health in work organizations: randomized controlled field trial. Journal of Applied Psychology, 97(2), 273.

64. Wang, P. S., Simon, G. E., Avorn, J., Azocar, F., Ludman, E. J., McCulloch, J., \& Kessler, R. C. (2007). Telephone screening, outreach, and care management for depressed workers and impact on clinical and work productivity outcomes: a 
randomized controlled trial. Journal of the American Medical Association, 298(12), 1401-1411.

65. Willert, M. V., Thulstrup, A. M., \& Bonde, J. P. (2011). Effects of a stress management intervention on absenteeism and return to work-results from a randomized wait-list controlled trial. Scandinavian journal of work, environment \& health, 37(3), 186-195.

66. Wolever, R. Q., Bobinet, K. J., McCabe, K., Mackenzie, E. R., Fekete, E., Kusnick, C. A., \& Baime, M. (2012). Effective and viable mind-body stress reduction in the workplace: a randomized controlled trial. Journal of occupational health psychology, 17(2), 246-258.

\section{ONLINE REFERENCES}

http://www.apa.org/helpcenter/work-stress.aspx. Last access Feb 27 $7^{\text {th }}, 2018$

http://www.hse.gov.uk/statistics/causdis/stress/stress.pdf. Last access Feb 27th, 2018 